\title{
$\mathrm{Mg}-\mathrm{Al}-\mathrm{Zn}-\mathrm{CaO}$ 합금의 부식 거동
}

\author{
문정현 · 전중환 ${ }^{\dagger}$ 김영직 * \\ 한국생산기술연구원 융합신공정연구그룹, *성균관대학교 공과대학 신소재공학부
}

\section{Corrosion Behavior of Mg-Al-Zn-CaO Alloy}

\author{
Jung-Hyun Moon, Joong-Hwan Jun ${ }^{\dagger}$ and Young-Jik Kim* \\ Advanced Fusion Process R\&D Group, Korea Institute of Industrial Technology, Incheon 406-840, Korea \\ *School of Advanced Materials Science \& Engineering, Sungkyunkwan University, Kyunggi-do 440-746, Korea
}

\begin{abstract}
The influences of a small amount of $\mathrm{CaO}$ addition on the microstructure and corrosion behavior of AZ81 casting alloy have been investigated by means of optical microscopy, scanning electron microscopy, X-ray photoelectron spectroscopy, immersion and electrochemical tests. The added $\mathrm{CaO}$ led to the refinement of $\alpha-\mathrm{Mg}$ grains and the decrease in $\beta$ precipitate content by the formation of an $\mathrm{Al}_{2} \mathrm{Ca}$ phase. The AZ81-CaO alloy had a better corrosion resistance than the AZ81 alloy. The microstructural characterization on the corroded surface revealed that the enhanced corrosion resistance of the CaO-containing alloy may well be ascribed to the increased barrier effect of precipitates formed more continuously along the grain boundaries and the incorporation of $\mathrm{Al}$ and $\mathrm{Ca}$ elements into the corrosion film, by which it became more protective.
\end{abstract}

Key words: $\mathrm{CaO}, \mathrm{ECO}-\mathrm{Mg}$, Microstructure, Corrosion properties

\section{1. 서 론}

마그네슘 $(\mathrm{Mg})$ 합금은 탁월한 경량성 이외 우수한 주조성, 절삭성, 진동 및 충격 흡수성, 전자파 차단성 등으로 인해 자 동차 및 휴대용 IT 관련 부품에 적용되고 있으며, 활용범위를 넓히기 위한 연구가 현재 다각도로 진행되고 있다[1,2]. 체심입 방구조 $(\mathrm{BCC})$ 인 $\mathrm{Mg}-\mathrm{Li}$ 합금을 제외한 모든 $\mathrm{Mg}$ 합금은 육방 조밀구조 $(\mathrm{HCP})$ 를 갖기 때문에 근본적으로 가공성이 취약하며, 따라서 $\mathrm{Mg}$ 부품은 주로 주조공정에 의해 제조되고 있다[3]. 이미 잘 알려져 있는 바와 같이 $\mathrm{Mg}$ 용탕은 공기와의 접촉에 의해 쉽게 발화되기 때문에 주조공정 중 공기와의 접촉을 차 단하기 위한 육불화황(sulfur hexafluoride, $\mathrm{SF}_{6}$ )과 같은 보호 가스의 사용이 불가피하다. 하지만 $\mathrm{SF}_{6}$ 가스는 탁월한 보호특 성에도 불구하고 지구온난화지수 $(\mathrm{GWP})$ 가 이산화탄소 $\left(\mathrm{CO}_{2}\right)$ 의 22,000 배에 달하는 온실가스로 전세계적으로 사용이 제한되고
있는 실정이다. 최근 $\mathrm{Kim}$ 등[4,5]은 $\mathrm{SF}_{6}$ 가스의 사용을 배제 하거나 사용량을 최소화할 수 있는 $\mathrm{ECO}-\mathrm{Mg}$ 소재를 개발하였 다. $\mathrm{ECO}-\mathrm{Mg}$ 은 상용합금에 소량(0.3 1.0 wt.\%)의 $\mathrm{CaO}$ 를 첨가한 것으로 용탕의 표면에 높은 밀도의 $(\mathrm{MgO}+\mathrm{CaO})$ 복합산화층을 형성, 공기와의 접촉을 효과적으로 차단하여 발화저항성을 향상 시키는 것으로 알려져 있다[4,5]. 이때 첨가된 $\mathrm{CaO}$ 는 용탕에서 $\mathrm{Ca}$ 로 환원되어 조직 내에 포함되는데, $\mathrm{Mg}$ 내의 낮은 고용도로 인해 $\mathrm{Ca}$ 원소의 대부분은 $\mathrm{Mg}_{2} \mathrm{Ca}, \mathrm{Al}_{2} \mathrm{Ca}$ 또는 $(\mathrm{Mg}, \mathrm{Al})_{2} \mathrm{Ca}$ 등 금속간화합물을 형성하여 결정립계나 아결정립계에 분포하게 되 며[6], 이로 인해 $\mathrm{CaO}$ 의 첨가는 상용 $\mathrm{Mg}$ 합금의 조직을 미 세화하고 이와 더불어 상-고온 기계적 특성을 향상시키는 추 가적인 효과가 나타나는 것으로 확인되고 있다[6-9].

현재 $\mathrm{Mg}$ 합금의 상용화에 가장 큰 문제점 중 하나는 낮은 내식성이다. $\mathrm{Mg}$ 합금의 부식 특성은 합금 내 불순물, 결정립 의 크기, 석출상의 분포 및 형상 등에 영향을 받는다고 알려
Received: April 22, 2013 ; Accepted: June 26, 2013

Corresponding author: Joong-Hwan Jun (KITECH)

Tel: +82-32-850-0425, Fax: +82-32-850-0430

E-mail: jhjun@kitech.re.kr
Journal of Korea Foundry Society

2013. Vol. 33 No. 3, pp. 127 133

http://dx.doi.org/10.7777/jkfs.2013.33.3.127

ISSN 1598-706X

(C) Korea Foundry Society, All rights reserved.

This is an Open-Access article distributed under the terms of the Creative Commons Attribution Non-Commercial License (http://creativecommons.org/licenses/by-nc/3.0) which permits unrestricted non-commercial use, distribution, and reproduction in any medium, provided the original work is properly cited. 
져 있으며[10-12], 표면처리와 미세조직 제어, 합금원소 첨가 등을 통해 이를 개선하기 위한 연구가 진행되고 있다[13-15]. 최근 $\mathrm{Nam}$ 등[16]은 $\mathrm{AZ91-(0} \mathrm{0.6)wt. \%} \mathrm{CaO}$ 합금에 대한 부식 거동을 조사한 결과, $\mathrm{CaO}$ 의 첨가량이 증가함에 따라 부 식저항성이 지속적으로 증가한다고 보고하였다. 하지만 이들의 연구는 $\mathrm{CaO}$ 의 영항을 전기화학적(electrochemical)인 방법으로 만 평가한 것으로, 보완되어 함께 이루어져야 할 무게감량 (weight loss)에 대해서는 조사가 이루어지지 않았다. Shi 등 [17]에 따르면 소재의 부식특성을 평가하기 위해서는 전기화학 적 방법 이외에 침지시험(immersion test), 염수분무시험(saltspray test), 수소방출량 측정 $\left(\mathrm{H}_{2}\right.$ evolution)과 같은 무게감량 관련 데이터가 제시되어야 하며, 따라서 $\mathrm{CaO}$ 가 첨가된 $\mathrm{Mg}$ 소 재에 대해서도 무게감량을 통한 부식저항성 평가가 필요하다고 생각된다. 본 연구에서는 $\mathrm{Mg}-\mathrm{Al}-\mathrm{Zn}$ 합금을 대상으로 Non-SF 6 공정이 가능한 최소한의 함량인 $~ 0.4 \mathrm{wt} \%$ 수준의 $\mathrm{CaO}$ 첨가 가 부식 거동에 미치는 영향을 전기화학 및 침지시험을 병행 하여 조사하고 이를 미세조직의 변화와 연관지어 분석하였다.

\section{2. 실험 방법}

$\mathrm{AZ81}$ 합금 및 $1.0 \mathrm{wt} \% \mathrm{CaO}$ 함유 $\mathrm{AZ81}$ 모합금을 이용하 여 목적 조성으로 평량한 후 전기저항로에서 재용해한 다음 $700^{\circ} \mathrm{C}$ 로 유지한 용탕을 $250^{\circ} \mathrm{C}$ 로 예열된 금형에 중력주조하였 다. 이때 $\mathrm{CaO}$ 가 첨가되지 않은 합금은 보호가스 $\left(\mathrm{SF}_{6}+\mathrm{CO}_{2}\right)$ 를 사용하여 주조하였고, $\mathrm{CaO}$ 가 첨가된 합금은 $\mathrm{CO}_{2}$ 가스만 사용 하여 주조하였다. 주조된 합금의 화학조성을 유도결합 플라즈마 (inductively coupled plasma, ICP)로 분석하였으며, 그 결과를

Table 1. Chemical compositions of experimental alloys (wt\%).

\begin{tabular}{ccccc}
\hline \multirow{2}{*}{ Alloy } & \multicolumn{4}{c}{ Chemical compositions (wt\%) } \\
\cline { 2 - 5 } & $\mathrm{Al}$ & $\mathrm{Zn}$ & $\mathrm{Ca}$ & $\mathrm{Mg}$ \\
\hline $\mathrm{AZ81}$ & 8.53 & 0.64 & - & $\mathrm{Bal}$. \\
$\mathrm{AZ81-0.4CaO}$ & 8.00 & 0.67 & 0.41 & $\mathrm{Bal}$. \\
\hline
\end{tabular}

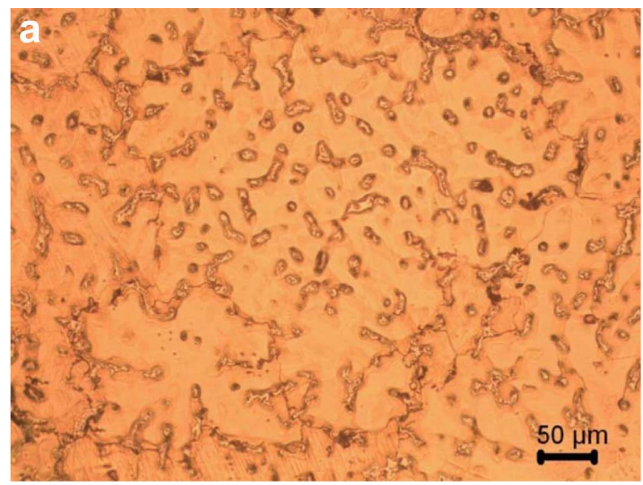

Table 1에 나타내었다. 실험에 사용된 $\mathrm{Mg}$ 합금 시편은 $60(\mathrm{~L}) \times$ $30(\mathrm{~W}) \times 2(\mathrm{~T}) \mathrm{mm}^{3}$ 크기로 제작하여 $\mathrm{SiC}$ 연마지로 \#4000까지 연마 후 알코올로 세척하여 사용하였다. 침지시험은 상온의 $5 \mathrm{wt} . \% \mathrm{NaCl}$ 수용액에서 각각 4시간, 48시간 동안 유지한 시편 을 크롬산(18wt.\% $\mathrm{CrO}_{3}+0.1 \mathrm{wt} \% \mathrm{AgNO}_{3}$ ) 용액에서 5분간 산세한 다음 에탄올로 세척 한 뒤 무게 변화를 측정하여 부식 속도(corrosion rate)를 계산하는 방법으로 진행하였다. 전기화학 시험은 작동전극에 $\mathrm{Mg}$ 시편, 상대전극에 고순도 탄소봉, 기준전 극에 포화감홍전극(saturated calomel electrode, $\mathrm{SCE}$ )을 사용하 여 상온의 $5 \mathrm{wt} . \% \mathrm{NaCl}$ 수용액에서 개방회로준위(open circuit potential, $\mathrm{OCP}$ )로 1시간 유지 후 진행하였다. 동전위 분극 (potentio-dynamic polarization) 시험은 Potentiostat (AMETEK VersaSTAT3)를 이용하여 $-2,400 \mathrm{mV}_{\mathrm{SCE}} \sim-400 \mathrm{mV}_{\mathrm{SCE}}$ 전위 범 위에서 $1 \mathrm{mV} / \mathrm{sec}$ 의 주사속도로 진행하였으며 Tafel 외삽법을 이용하여 부식전위 $\left(\mathrm{E}_{\mathrm{corr}}\right)$ 값과 부식전류밀도 $\left(\mathrm{i}_{\mathrm{corr}}\right)$ 값을 구하였다. 또한, $100 \mathrm{kHz} \sim 100 \mathrm{mHz}$ 의 주파수 범위에서 전기화학적 임피 던스 분광법(electrochemical impedance spectroscopy, EIS)으 로 임피던스 데이터를 측정하였다. 시편의 미세조직은 광학현미 경(OM, Nikon Epiphot 200BD)과 주사전자현미경(SEM, FEI Quanta 200F)으로 관찰하였고, 에너지 분산 X-선 분광기 (EDS, AMETEK PV72-60030F)와 X-선 광전자 분광기(XPS, Thermo VG Scientific Multilab 2000)를 이용하여 부식생성 물을 분석하였다.

\section{3. 결과 및 고찰}

\section{1 미세조직}

Fig. 1은 중력주조한 AZ81 합금과 AZ81-0.4CaO 합금의 $\mathrm{OM}$ 미세조직으로, $\mathrm{CaO}$ 의 미량 첨가로 인해 결정립의 크기가 줄어들고 결정립계에 주로 분포해있는 $\beta-\mathrm{Mg}_{17} \mathrm{Al}_{12}$ 상이 약간 미세해지는 것이 관찰된다. 영상분석기(image analyzer)로 미세 조직을 분석한 결과, AZ81 합금과 AZ81-0.4CaO 합금의 결 정립 크기는 각각 $59 \mu \mathrm{m}, 49 \mu \mathrm{m}$ 로 확인되었으며, $\beta$ 상의 양은

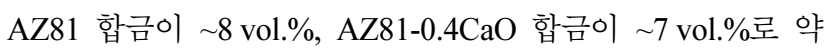

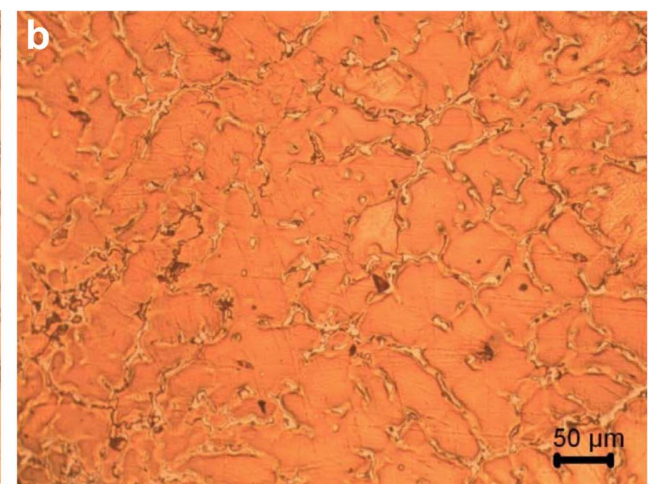

Fig. 1. Optical microstructures of (a) AZ81 and (b) AZ81-0.4CaO alloys in as-cast state. 

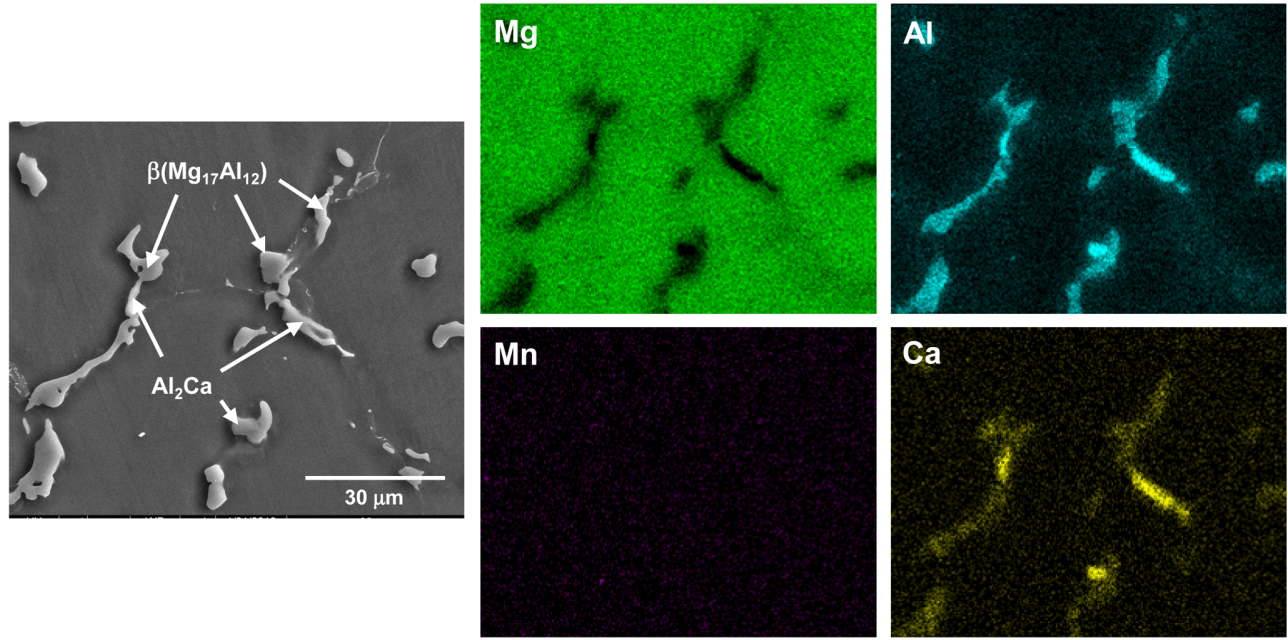

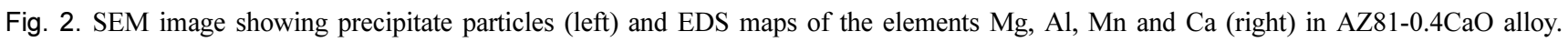

간 감소하는 것으로 나타났다. $\mathrm{CaO}$ 첨가로 인한 $\mathrm{Mg}-\mathrm{Al}$ 계 합 금의 결정립 미세화와 $\beta$ 상의 함량 감소는 $\mathrm{Cho}$ 등[8]의 연구 결과에서도 이미 확인된 바 있으며, $\mathrm{Ca}$ 첨가에 따른 $\mathrm{Mg}-\mathrm{Al}$ 계 합금의 미세조직 변화와도 유사하다. Wang 등[18]은 AZ91$\mathrm{Ca}$ 합금의 미세조직을 관찰한 결과 $\mathrm{Ca}$ 함량이 증가함에 따라 $\beta$ 상이 구조적 안정성과 원자간 친화도가 높은 $\mathrm{Al}_{2} \mathrm{Ca}$ 상으로 대 체되면서 함량이 점차 감소한다고 보고하였다. 한편, Fig. 1 로 부터 $\mathrm{CaO}$ 가 첨가된 합금에서 결정립계에 형성된 $\beta$ 상이 $\mathrm{CaO}$ 가 첨가되지 않은 합금과 비교하여 더 연속적으로 분포되고 있는 것이 관찰되는데 이는 결정립 크기 감소와 관련이 있다 고 판단된다. Fig. 2는 $\mathrm{AZ} 81-0.4 \mathrm{CaO}$ 합금의 $\mathrm{SEM}$ 미세조직 과 $\mathrm{Mg}, \mathrm{Al}, \mathrm{Mn}, \mathrm{Ca}$ 원소들에 대한 $\mathrm{EDS}$ mapping 결과를 나타낸 것이다. 이 결과로부터, $\beta$ 상과 인접하여 $\mathrm{Al}_{2} \mathrm{Ca}$ 상이 미 량 형성되어 있고 $\beta$ 상 내부에 $\mathrm{Ca}$ 원소가 불균일하게 분포되 어 있음을 확인할 수 있다. 이 결과는 $\mathrm{CaO}$ 로부터 환원된 $\mathrm{Ca}$ 가 $\mathrm{Al}_{2} \mathrm{Ca}$ 상의 생성에 관여함과 동시에 일부 $\beta$ 상에도 포함됨을 의미하는 것이다. 이와 같은 결과는 Regev 등[19]의 보고와도 일치하는 것으로, $\mathrm{Mg}-\mathrm{Al}$ 합금에서 $\mathrm{Ca}$ 는 $\mathrm{Mg}$ 기지의 낮은 고 용도로 인해 $\beta$ 상에 포함될 수 있으며 이때 $\beta$ 상을 구성하는 $\mathrm{Mg}$ 원자의 일부가 $\mathrm{Ca}$ 로 대체되면서 용융온도와 고온에서의 열적 안정성을 향상시킨다고 주장하였다.

\section{2 부식 특성}

Fig. 3은 AZ81과 AZ81-0.4CaO 합금을 $5 \mathrm{wt} . \% \mathrm{NaCl}$ 수 용액에서 각각 4시간, 48시간 침지시험한 후 부식속도를 측정 한 결과이다. 4시간 후 부식속도는 AZ81 합금과 AZ81$0.4 \mathrm{CaO}$ 합금이 각각 $0.79,0.37 \mathrm{mg} / \mathrm{cm}^{2} / \mathrm{day}, 48$ 시간 후 부식 속도는 각각 $0.70,0.30 \mathrm{mg} / \mathrm{cm}^{2} / \mathrm{day}$ 로 침지시간에 관계없이 $\mathrm{CaO}$ 가 첨가된 합금의 부식속도가 $\mathrm{CaO}$ 가 첨가되지 않은 합금 의 $\sim 50 \%$ 이하 수준에 불과했다. Fig. 4는 4시간과 48 시간 침지시험한 시편의 미세조직을 $\mathrm{OM}$ 으로 관찰한 결과이다. $\mathrm{Fig}$.

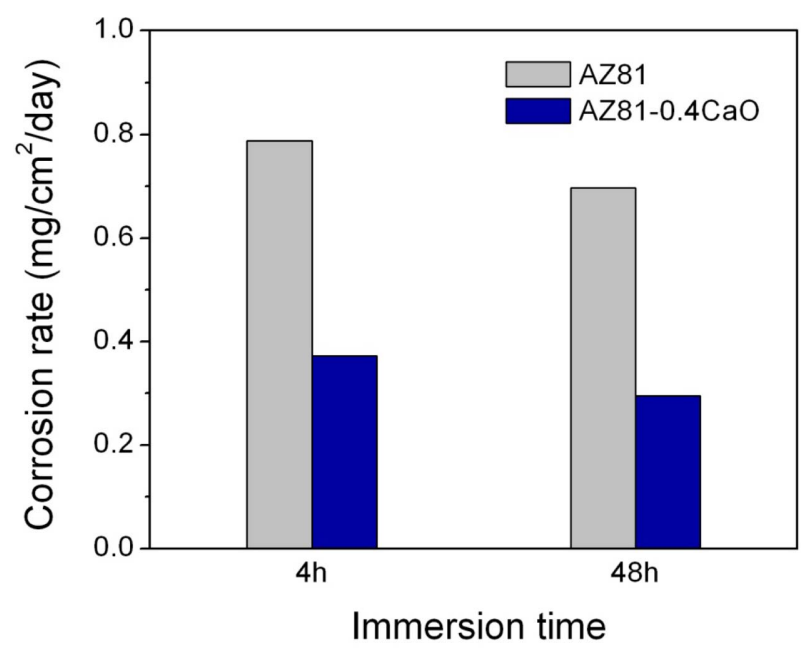

Fig. 3. Corrosion rates calculated from weight loss after immersion tests for AZ81 and AZ81-0.4CaO alloys.

4-(a)와 (b)는 4시간 침지시험 후의 조직사진으로, 초기 부식이 $\alpha-\mathrm{Mg}$ 과 $\beta$ 상의 경계에서 발생하는 것을 확인할 수 있으며, 이 는 $\alpha-\mathrm{Mg}$ 과 $\beta$ 상이 마이크로 갈바닉 셀을 형성하여 전위차에 의해 부식이 시작되기 때문이다. Fig. 4-(c)와 (d)는 48시간 침 지시험 후 조직사진으로, AZ81 합금에서는 $\beta$ 상이 결정립계를 따라 불연속적으로 분포되어 있어 $\alpha-\mathrm{Mg}$ 에 발생한 부식의 전 파를 효과적으로 방해하지 못하며 부식에 의해 $\alpha-\mathrm{Mg}$ 이 소멸 되면서 $\beta$ 상이 떨어져 나가 고립되는 모습이 관찰되는 반면 (Fig. 4-(c)), $\mathrm{CaO}$ 가 첨가된 합금에서는 보다 연속적으로 분포 된 $\beta$ 상이 장애물(barrier) 역할을 함으로써 AZ81 합금보다 부 식의 전파를 더욱 효과적으로 억제하는 모습을 확인할 수 있 다(Fig. 4-(d)). Song 등[20]은 Mg-Al 합금에서 생성되는 금 속간화합물인 $\beta$ 상이 그 자체로 $\alpha-\mathrm{Mg}$ 에 비해 부식저항성이 매 우 뛰어나며, $\alpha-\mathrm{Mg}$ 과 공존할 경우 이중 역할(dual role)을 한 

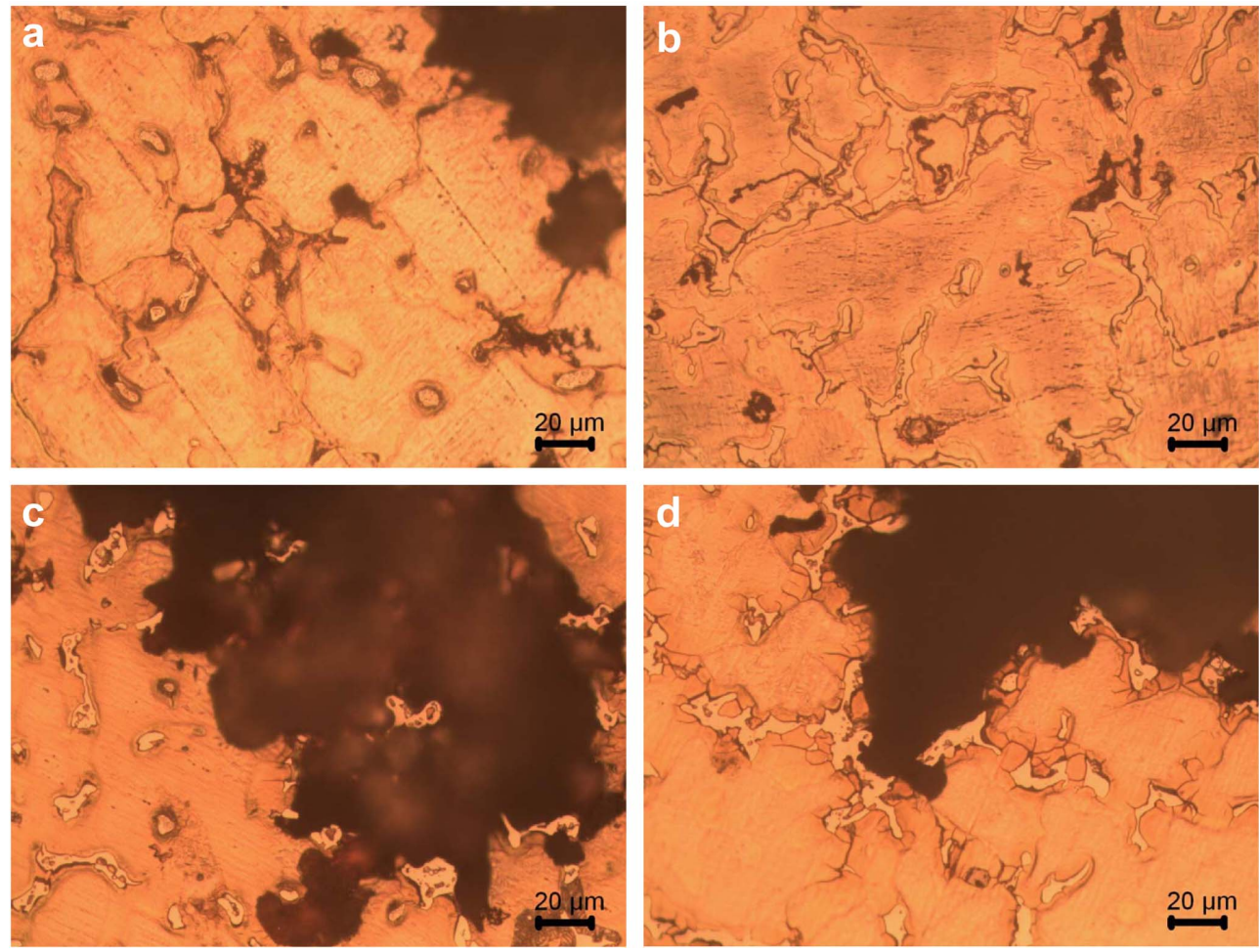

Fig. 4. Optical microstructures of corrosion surface morphology for AZ81 and AZ81-0.4CaO alloys after immersion test : (a) AZ81-4h, (b) AZ81-0.4CaO-4h, (c) AZ81-48h and (d) AZ81-0.4CaO-48h.

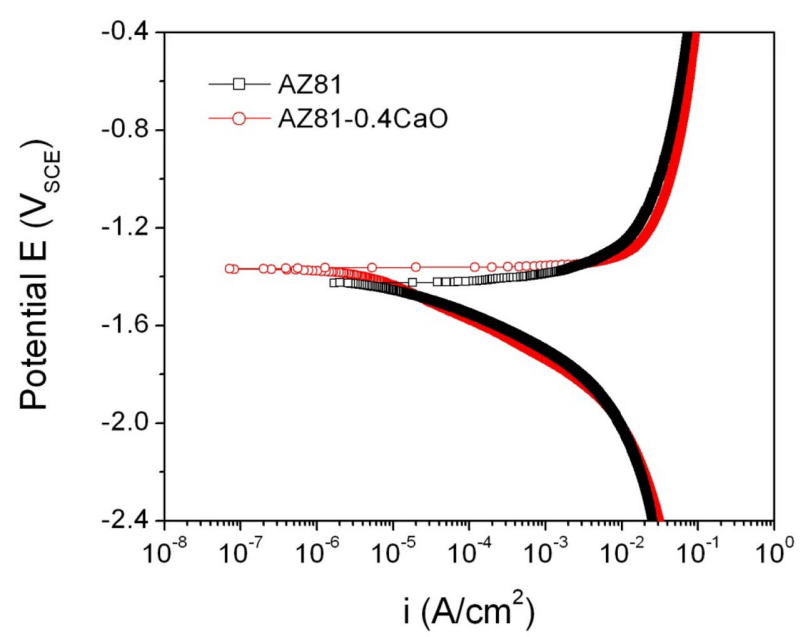

Fig. 5. Potentiodynamic polarization curves of AZ81 and AZ81$0.4 \mathrm{CaO}$ alloys.

다고 주장하였다. 즉, $\beta$ 상은 부식의 전파를 막는 장애물로 작 용할 수도 있고 반대로 갈바닉 음극(galvanic cathode) 역할을 하여 부식속도를 가속화시킬 수도 있다는 것이다. 어떤 역할이 부식에 있어 더 우세하게 작용하는지는 $\beta$ 상의 양과 분포양상에 의존하는데, 만약 $\beta$ 상이 미세하게 연속적으로 분포해 있다면 불연속적으로 분포하는 경우와 비교하여 갈바닉 음극으로 작용
Table 2. Electrochemical corrosion data for AZ81 and AZ81$0.4 \mathrm{CaO}$ alloys in $5 \mathrm{wt} . \% \mathrm{NaCl}$ solution.

\begin{tabular}{cccc}
\hline Alloy & $\begin{array}{c}\mathrm{E}_{\text {corr }} \\
\left(\mathrm{V}_{\mathrm{SEE}}\right)\end{array}$ & $\begin{array}{c}\mathrm{i}_{\text {corr }} \\
\left(10^{-4} \mathrm{~A} / \mathrm{cm}^{2}\right)\end{array}$ & $\begin{array}{c}\text { Corrosion rate } \\
(\mathrm{mm} / \mathrm{y})\end{array}$ \\
\hline $\mathrm{AZ81}$ & -1.427 & 0.083 & 0.190 \\
$\mathrm{AZ81-0.4CaO}$ & -1.368 & 0.039 & 0.089 \\
\hline
\end{tabular}

하는 표면적이 작아지고 이와 더불어 부식 전파를 억제하는 장애물로서의 역할도 더욱 효과적으로 수행할 수 있으므로 부 식속도는 감소하게 된다.

Fig. 5는 AZ81과 AZ81-0.4CaO 합금의 동전위 분극(potentiodynamic polarization) 시험 결과이다. 이 곡선으로부터 Tafel 외삽법[21]을 이용하여 부식전위 $\left(\mathrm{E}_{\mathrm{corr}}\right)$ 와 부식전류밀도 $\left(\mathrm{i}_{\mathrm{corr}}\right)$ 를 구하였으며 다음 식[22]을 통해 부식속도(mm/year)를 계산하여 함께 Table 2에 나타내었다.

$$
\text { Corrosion rate }=\left(22.85 \times \mathrm{i}_{\text {corr }}\left(\mathrm{mA} / \mathrm{cm}^{2}\right)\right)
$$

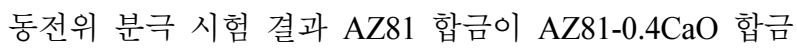

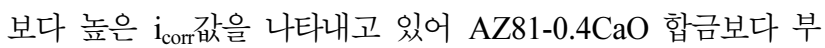
식속도가 더 높은 것을 알 수 있으며, 이러한 결과는 Fig. 3 에 나타낸 침지시험 결과와도 잘 일치한다. Fig. 6은 100 $\mathrm{kHz} \sim 100 \mathrm{mHz}$ 의 주파수 범위에서 전기화학적 임피던스 분광 

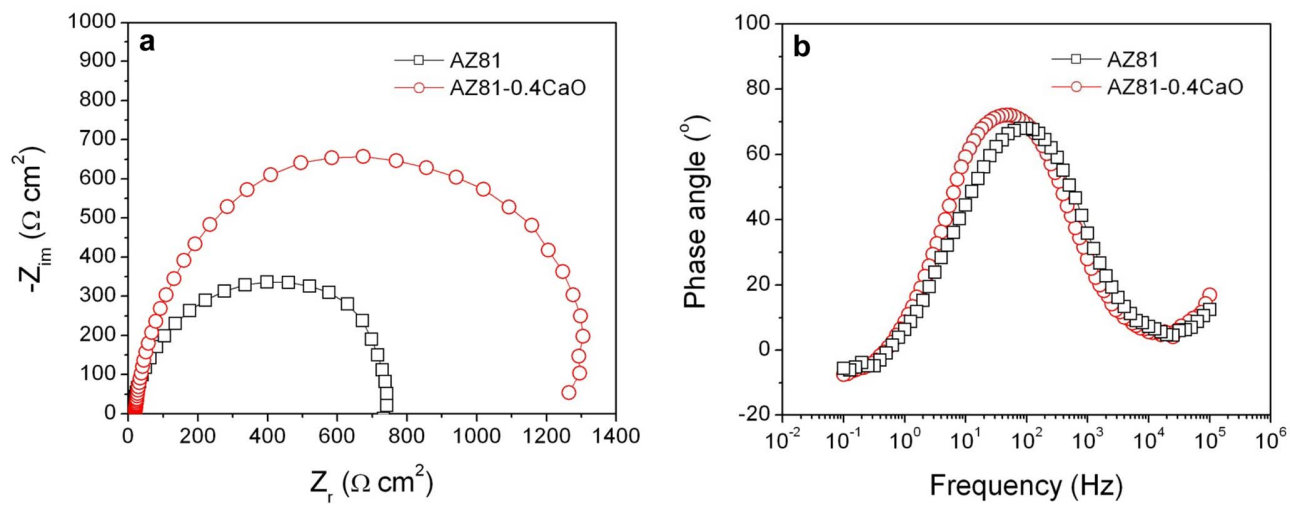

Fig. 6. (a) Nyquist and (b) Bode plots of AZ81 and AZ81-0.4CaO alloys.

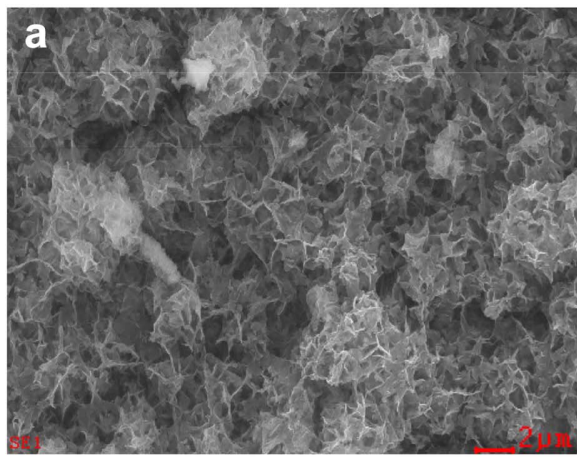

$\overline{2 \mu \mathrm{m}}$

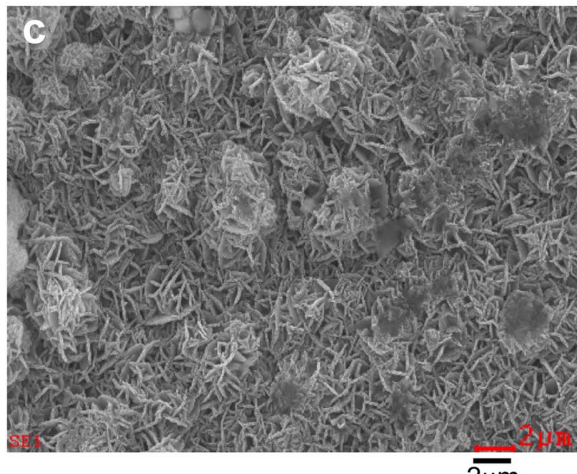

$\overline{2 \mu \mathrm{m}}$
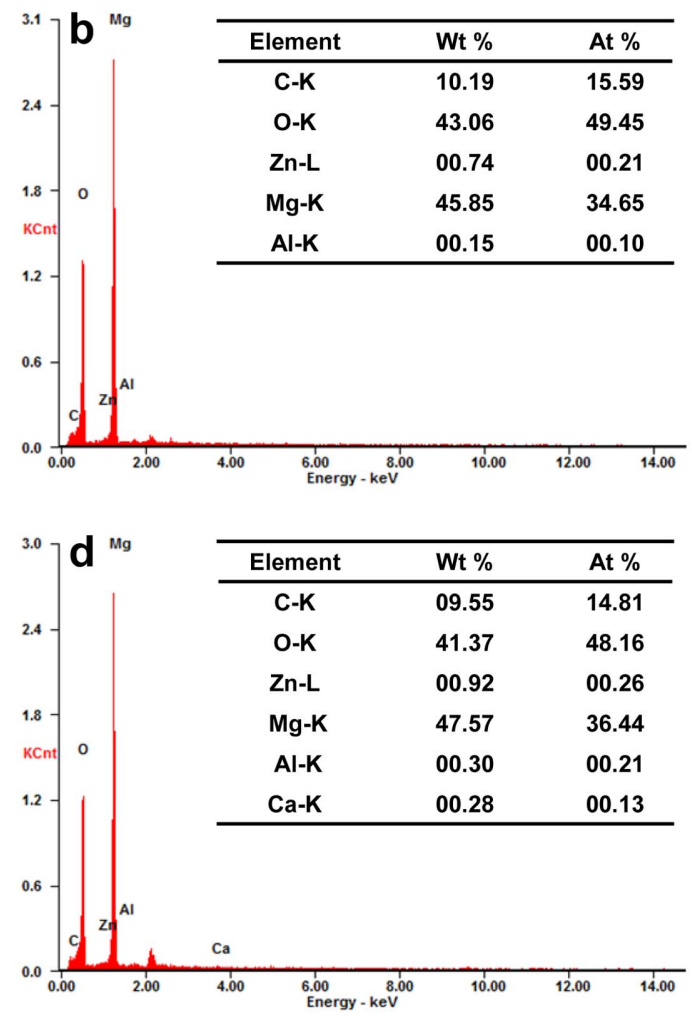

Fig. 7. SEM microstructures and EDS analyses of corrosion products for AZ81 and AZ81-0.4CaO alloys : (a), (b) AZ81 and (c), (d) AZ81$0.4 \mathrm{CaO}$ alloys, respectively.

법(EIS)으로 얻은 임피던스 데이터를 나타낸 것이다. Fig. 6(a)는 임피던스의 실수부 $\left(Z_{\mathrm{r}}\right)$ 와 허수부 $\left(-Z_{\mathrm{im}}\right)$ 를 주파수의 함수로 나타낸 그래프로 Nyquist plot이라 불리고, Fig. 6-(b)는 위상 각을 주파수의 함수로 나타낸 그래프로 Bode plot이라 불린다. 일반적으로 Nyquist plot에서 $-Z_{\mathrm{im}}$ 의 최대값이 클수록 부식특 성이 우수하며[23], Bode plot은 $45^{\circ}$ 위상각에 대한 주파수가 저주파일수록 도막 박리에 대한 저항이 크다고 알려져 있다 [24]. EIS 실험 결과 Nyquist plot과 Bode plot 모두 AZ81 합금보다 $\mathrm{AZ} 81-0.4 \mathrm{CaO}$ 합금의 부식저항성이 우수한 것으로
나타났으며, 이는 이전 $\mathrm{CaO}$ 첨가 $\mathrm{AZ91}$ 합금에서 보고된 결 과와도 동일하다[16].

Fig. 7과 8 은 $\mathrm{CaO}$ 첨가가 부식생성물에 미치는 영향을 파 악하기 위해 48시간 침지시험 후 시편의 표면에 형성된 부식 생성물을 각각 SEM-EDS 및 XPS로 분석한 결과이다. Fig. 7의 (a)와 (c)는 각 합금의 부식생성물에 대한 SEM 사진으로

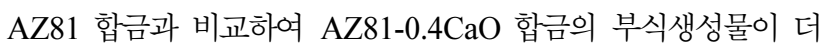
미세하고 밀도가 높은 것을 관찰할 수 있다. Fig. 7의 (b)와 (d)의 $\mathrm{EDS}$ 분석결과를 살펴보면 $\mathrm{AZ} 81-0.4 \mathrm{CaO}$ 합금의 부식생 

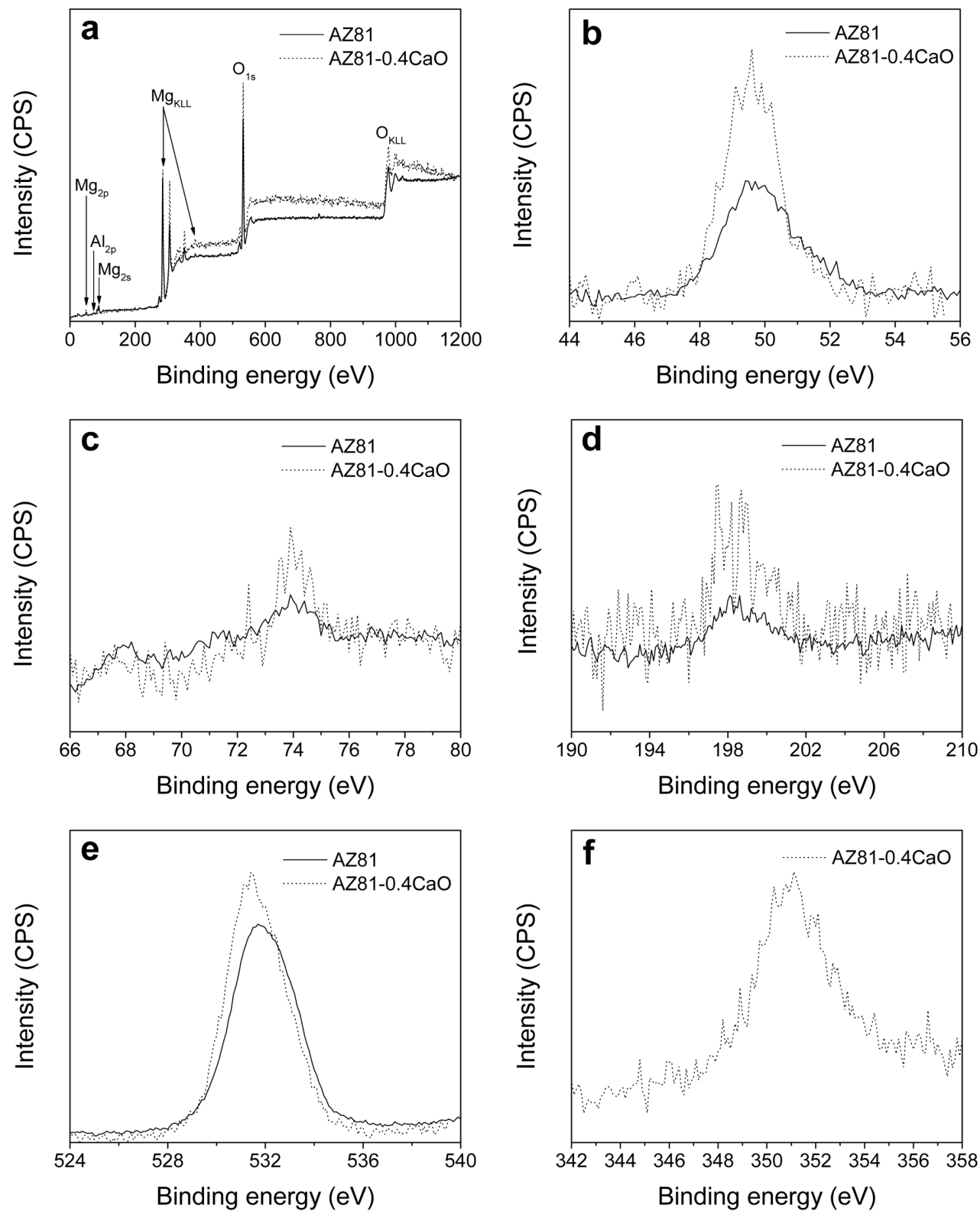

Fig. 8. XPS analyses of corrosion products for AZ81 and AZ81-0.4CaO alloys : (a) survey scan spectra and narrow scan spectra of (b) Mg, (c) $\mathrm{Al}$, (d) $\mathrm{Cl}$, (e) $\mathrm{O}$ and (f) $\mathrm{Ca}$.

성물이 $\mathrm{Ca}$ 를 포함하고 있으며 상대적으로 $\mathrm{Al}$ 의 함량도 $\mathrm{AZ81}$ 합금에 비해 더 높은 것을 알 수 있다. 한편, Fig. 8의 XPS 스팩트럼에서는 $\mathrm{Al}$ 및 $\mathrm{O}$ 원소에 대한 피크 강도가 $\mathrm{AZ81}$ 합

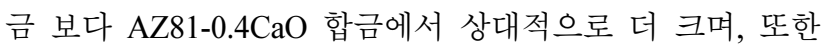
$\mathrm{Ca}$ 원소에 대한 피크가 $\mathrm{AZ81}-0.4 \mathrm{CaO}$ 합금에서 검출되고 있 는데 이러한 결과는 앞의 $\mathrm{EDS}$ 결과와 잘 일치하는 것이다. Fig. 7과 8의 결과들은 $\mathrm{AZ} 81-0.4 \mathrm{CaO}$ 합금의 부식생성물이 $\mathrm{Al}_{2} \mathrm{O}_{3}, \mathrm{Al}(\mathrm{OH})_{3}$ 와 같은 화합물을 더 많이 포함하고 있으며 [16], 또한 $\mathrm{AZ81}$ 합금에서는 존재하지 않는 $\mathrm{CaO}, \mathrm{Ca}(\mathrm{OH})_{2}$ 와 같은 화합물이 추가적으로 부식생성물 내에 도입되어 있음을
의미한다. 이와 같은 $\mathrm{Al}$ 계, $\mathrm{Ca}$ 계 산화물 및 수산화물의 증가 는 부식생성물의 밀도를 높여 안정성(stability)을 향상시키기 때문에 $\mathrm{Cl}^{-}, \mathrm{CO}_{3}{ }^{2-}$ 와 같이 부식과 관련된 해로운 양이온의 침 투를 더 효과적으로 억제하게 된다[25]. Fig. 4의 미세조직, Fig. 7과 8의 표면 분석결과를 종합해보면, $\mathrm{Mg}-\mathrm{Al}-\mathrm{Zn}$ 합금에 서 $\mathrm{CaO}$ 의 첨가는 결정립계에 존재하는 정출상의 연속성을 향 상시켜 $\alpha-\mathrm{Mg}$ 기지를 통한 부식전파를 더욱 효과적으로 억제 하고, 다른 한편으로는 부식생성물 내에 $\mathrm{Al}$ 계, $\mathrm{Ca}$ 계 산화물 및 수산화물의 밀도를 증가시켜 $\mathrm{Cl}^{-}, \mathrm{CO}_{3}{ }^{2-}$ 와 같은 이온들의 침투를 효과적으로 억제하는데 기여하여 부식저항성을 항상시키 
는 것으로 판단된다.

\section{4. 결 론}

본 연구는 중력주조한 AZ81 합금의 미세조직과 부식저항성 에 미치는 미량 $\mathrm{CaO}$ 첨가의 영향을 분석하기 위해 진행되었 다. $0.4 \mathrm{wt} . \% \mathrm{CaO}$ 첨가로 인해 $\mathrm{AZ} 81$ 합금의 결정립 크기와 $\beta$ 상의 함량이 감소하였지만 결정립계를 따라서 형성된 $\beta$ 상의 분포는 보다 연속적인 형태를 나타내었다. AZ81- $0.4 \mathrm{CaO}$ 합금 의 경우 $\mathrm{CaO}$ 로부터 환원된 $\mathrm{Ca}$ 로 인해 미세조직 내에 미량의 $\mathrm{Al}_{2} \mathrm{Ca}$ 상이 생성되었으며 $\beta$ 상의 내부에 $\mathrm{Ca}$ 성분이 불균일하게 분포하는 것이 관찰되었다. 침지시험 및 전기화학시험 결과

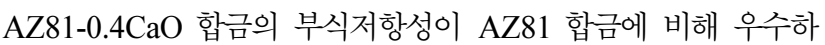
였는데, 부식 후 미세조직에 대한 $\mathrm{OM}$ 분석 및 부식생성물에 대한 SEM-EDS, XPS 분석 결과 $\mathrm{CaO}$ 첨가로 인한 부식저항 성 향상의 원인은 $\beta$ 상이 결정립계를 따라 더욱 연속적으로 분 포하여 $\alpha-\mathrm{Mg}$ 기지를 통한 부식전파를 더욱 효과적으로 억제 하는 점과 부식생성물 내에 $\mathrm{Al}$ 계, $\mathrm{Ca}$ 계 산화물 및 수산화물의 도입으로 안정성을 향상시켜 $\mathrm{Cl}^{-}, \mathrm{CO}_{3}{ }^{2-}$ 와 같은 이온들의 침투 를 효과적으로 억제하는 점이 복합적으로 작용하였기 때문으로 생각된다.

\section{감사의 글}

본 연구에 사용된 $\mathrm{CaO}$ 첨가 합금은 한국생산기술연구원 김 세광 박사로부터 제공되었으며 이에 감사드립니다.

\section{참고문헌}

[1] Mordike BL and Ebert T, Mater. Sci. Eng. A, "Magnesium: Properties - Applications - Potential”, 302 (2001) 37-45.

[2] Friedrich H and Schumann S, J. Mater. Proc. Tech., "Research for 'A New Age of Magnesium' in the Automotive Industry", 117 (2001) 276-281.

[3] Caceres CH, Davidson CJ, Griffiths JR and Newton CL, Mater. Sci. Eng. A, "Effects of Solidification Rate and Ageing on the Microstructure and Mechanical Properties of AZ91 Alloy”, 325 (2002) 344-355.

[4] Lee JK and Kim SK, Mater. Trans., "Effect of $\mathrm{CaO}$ Addition on the Ignition Resistance of Mg-Al Alloys", 52 (2011) 14831488.

[5] Ha SH, Lee JK and Kim SK, Mater. Trans., "Effect of $\mathrm{CaO}$ on Oxidation Resistance and Microstructure of Pure Mg", 49 (2008) 1081-1083.

[6] Jang DI, Yoon YO, Jung SB and Kim SK, Mater. Trans., "Effect of CaO on AZ31 Mg Strip Castings", 49 (2008) 976-979.

[7] Lim HK, Kim SK and Kim DH, J. Korean Foundry Soc., "Effect of Alloying Elements on Creep Behavior of Mg-Al
Alloys", 32 (2012) 44-49.

[8] Cho EH, Jun JH and Kim YJ, Kor. J. Mater. Res., "Microstructure and Mechanical Properties at Room and Elevated Temperatures in AM50-0.3wt\%CaO Alloy", 22 (2012) 499503.

[9] Jun JH, Mater. Trans., "Effect of $\mathrm{CaO}$ Addition on Microstructure and Damping Capacity of AM50 Magnesium Alloy", 54 (2013) 409-411.

[10] Song GL and Atrens A, Corr. Sci. Tech., "Magnesium Corrosion Mechanisms", 31 (2002) 103-115.

[11] Song GL and Atrens A, Adv. Eng. Mater., "Understanding Magnesium Corrosion-A Framework for Improved Alloy Performance", 5 (2003) 837-858.

[12] Yim CD, Kim YM, Park SH and You BS, Korean J. Met. Mater., "Corrosion Behavior of AZ91 Magnesium Alloy", 9 (2012) 619-627.

[13] He MF, Liu L, Wu YT, Tang ZX and Hu WB, Corr. Sci., "Corrosion Properties of Surface-modified AZ91D Magnesium Alloy", 50 (2008) 3267-3273.

[14] Ralston KD, Birbilis N, and Davies CHJ, Scripta Mater., "Revealing the Relationship between Grain Size and Corrosion Rate of Metals", 63 (2010) 1201-1204.

[15] Song GL, Adv. Eng. Mater., "Recent Progress in Corrosion and Protection of Magnesium Alloys", 7 (2005) 563-586.

[16] Nam ND, Bian MZ, Forsyth M, Seter M, Tan M and Shin KS, Corr. Sci., "Effect of Calcium Oxide on the Corrosion Behaviour of AZ91 Magnesium Alloy", 64 (2012) 263-271.

[17] Shi ZM, Liu M and Atrens A, Corr. Sci., "Measurement of the Corrosion Rate of Magnesium Alloys Using Tafel Extrapolation", 52 (2010) 579-588.

[18] Wang Q, Chen W, Zeng X, Liu Y, Ding W, Zhu Y, Xu X and Mabuchi M, J. Mater. Sci., "Effects of Ca Addition on the Microstructure and Mechanical Properties of AZ91 Magnesium Alloy", 36 (2001) 3035-3040.

[19] Regev M, Aghion E and Rosen A, Mater. Sci. Eng. A, "Creep studies of AZ9ID Pressure Die Casting”, 234-236 (1997) 123126.

[20] Song GL and Atrens A, Adv. Eng. Mater., "Corrosion Mechanisms of Magnesium Alloys", 1 (1999) 11-33.

[21] Jones DA, Principles and Prevention of Corrosion (2nd Edition), Prentice-Hall Inc (1996).

[22] Zhao MC, Schmutz P, Brunner S, Liu M, Song GL and Atrens A, Corr. Sci., "An Exploratory Study of the Corrosion of $\mathrm{Mg}$ Alloys during Interrupted Salt Spray Testing", 51 (2009) 1277-1292.

[23] Lee WJ and Pyun SI, J. Corr. Sci. Soc. of Korea, "Fundamentals and Applications of Electrochemical Impedance Spectroscopy to Corrosion Sciences", 26 (1997) 120-140.

[24] Kim JT, Jeong HS, Ryu SS, Lee GD and Park JM, Korean Chem. Eng. Res., "Anti-Corrosion Performance of the Novel Pigment, Ion-Exchanged Zeolite for the Protection of Galvanized Steel", 49 (2011) 745-751.

[25] Song YL, Liu YH, Yu SR, Zhu XY and Wang SH, "Effect of Neodymium on Microstructure and Corrosion Resistance of AZ91 Magnesium Alloy", 42 (2007) 4435-4440. 